Proc. of the XI Int. Conf. - Ion Implantation and other Applications of Ions and Electrons, Kazimierz Dolny 2016

\title{
Structure and Physicomechanical Properties of Nanostructured (TiHfZrNbVTa)N Coatings after Implantation of High Fluences of $N^{+}\left(10^{18} \mathrm{~cm}^{-2}\right)$
}

\author{
A.D. Pogrebnjak ${ }^{a, b, *}$, O.V. Bondar ${ }^{a}$, S.O. Borba ${ }^{a}$, K. Piotrowska ${ }^{c}$ And O. Boiko ${ }^{b}$ \\ ${ }^{a}$ Sumy State University, Department of Nanoelectronics, R.-Korsakova 2, 40007, Sumy, Ukraine \\ ${ }^{b}$ Department of Electrical Devices and High Voltage Technology, Lublin University of Technology, \\ 20-618 Lublin, Poland \\ ${ }^{c}$ Institute of Technological Systems of Information, Lublin University of Technology, 20-618 Lublin, Poland
}

New classes of high-entropy alloys, which consist of at least 5 main elements with atomic concentrations 535 at.\%, are under great interest in modern material science. It is also very important to explore the limits of resistance of high-entropy alloy nitrides to implantation by high-energy atoms. Structure and properties of nanostructured multicomponent (TiHfZrNbVTa) N coatings were investigated before and after ion implantation. We used the Rutherford backscattering, scanning electron microscopy with energy dispersive X-ray spectroscopy, high resolution transmission electron microscopy and scanning transmission electron microscopy with local microanalysis, X-ray diffraction and nanoindentation for investigations. Due to the high-fluence ion implantation $\left(N^{+}\right.$, the fluence was $10^{18} \mathrm{~cm}^{-2}$ ) a multiphase structure was formed in the surface layer of the coating. This structure consisted of amorphous, nanocrystalline and initial nanostructured phases with small sizes of nanograins. Two phases were formed in the depth of the coating: fcc and hcp (with a small volume fraction). Nitrogen concentration reached 90 at.\% near the surface and decreased with the depth. Nanohardness of the as-deposited coatings varied from 27 to $34 \mathrm{GPa}$ depending on the deposition conditions. However, hardness decreased to a value of $12 \mathrm{GPa}$ of the depth of the projected range after ion implantation and increased to $23 \mathrm{GPa}$ for deeper layers.

DOI: 10.12693/APhysPolA.132.217

PACS/topics: 61.46.--w, 62.20.Qp

\section{Introduction}

Ion implantation, by which ions of a material are accelerated in an electrical field and impacted into a solid, is well-known in the materials science and engineering [1-5]. This process is used to change the physical-mechanical, tribological, chemical, or electrical properties of the solid [3-10]. The ions alter the elemental composition of the target, stopping in the target and staying there, causing many chemical and physical changes in the target by transferring their energy and momentum to the electrons and atomic nuclei of the target material. In its turn, it causes a structural change, in that the crystal structure of the target can be damaged or even destroyed by the energetic collision cascades. As the masses of the implanted ions are comparable to those of the target atoms, the implanted ions knock the target atoms out of place even more than electron beams do [5-18]. The main advantage of ion implantation is preservation of sample sizes, locality (small projected range), high reproducibility, no problems with adhesion, etc., which allows using it in various technological processes. In order to improve the properties of metals, alloys and ceramics, it is necessary to use high fluences of ion implantation,

\footnotetext{
*corresponding author; e-mail: alexp@i.ua
}

typically $10^{16} \div 10^{17} \mathrm{~cm}^{-2}$. However, sometimes it is necessary to use an extra high fluence of implantation around $10^{18} \mathrm{~cm}^{-2}$, which corresponds to the amount of atoms $(1-5) \times 10^{21} \mathrm{~cm}^{-3}$ in the implanted volume.

Nitride coatings from the high-entropy alloys (HEAN), which consist of at least 5 atoms with atomic content from 5 to 35 at.\%, are under great interest in modern materials science because of improved physical and mechanical characteristics [19]. One-phase stable substitutional solid solution with fcc or bcc lattice is usually formed in such high-entropy alloys, and this is the reason for further intensive investigations. Formation of nitrides and carbides from high-entropy alloys is also a current task of modern materials science, because such materials have much higher wear, corrosion and oxidation resistance, higher hardness and plasticity in comparison with clear highentropy alloys. The task of clarifying the limits of resistance of such nitride coatings to oxidation and irradiation resistance after $\mathrm{Cu}^{-}, \mathrm{Au}^{-}, \mathrm{N}^{+}$ion implantation, as well as influence of ion implantation on hardness, plasticity index and corrosion resistance of HEAN coatings were discussed in the papers [14, 20-22]. High fluences of implantation $\left(1-2 \times 10^{17} \mathrm{~cm}^{-2}\right)$ led to improving different mechanical characteristics, such as hardness [23, 24]. However, the overview of published studies shows that the used implantation fluence ranges are quite small, especially for improving physicomechanical characteristics [2528]. By the way, there are no studies on implantation of high fluences of $\mathrm{N}^{+}$ions (up to $10^{18} \mathrm{~cm}^{-2}$ ), when the 
fluence of implanted ions may reach the atomic concentration of the material $\left(10^{23} \div 5 \times 10^{23} \mathrm{~cm}^{-3}\right)$.

Thus, the aim of our work is to study the microstructure and physical-mechanical properties of nanostructured multielement coatings, implanted by high fluences (up to $10^{18} \mathrm{~cm}^{-2}$ ) of $\mathrm{N}^{+}$ions.

\section{Experimental details}

Cathodes from the high entropy alloys of TiZrHfVNbTa system were produced by vacuum-arc melting in the atmosphere of high purity argon using a nonconsumable electrode into a water-cooled copper vessel. To fabricate a homogeneous composition of the alloy, the ingots were 6-7 times remelted.

Nitride coatings were deposited by vacuum-arc evaporation of a cathode in a Bulat-3T-M device [4]. We deposited two series of samples on the steel disks (A 570 Grade 26 - high-alloy stainless steel X12H18T9, its content C $-0.12 \%, \mathrm{Ni}-9 \%, \mathrm{Cr}-18 \%, \mathrm{Ti}-1 \%$, the rest is $\mathrm{Fe}$ ) with the $45 \mathrm{~mm}$ diameter and $4 \mathrm{~mm}$ thickness at different pressure in the deposition chamber $\left(P_{N}\right)$, while the bias voltage, applied to the substrate $\left(U_{b}\right)$ remained the same for each series and equalled to $-150 \mathrm{~V}$. Thus, for the first series $P_{N}=3 \times 10^{-3}$ Torr and for the second one $P_{N}=7 \times 10^{-4}$ Torr. The impulse mode of deposition was selected to increase the energy of ion-plasma flow, improve adhesion of deposited coatings to a substrate, and to obtain a more dispersive structure of coatings.

Ion implantation by $\mathrm{N}^{+}$ions with the energy $60 \mathrm{keV}$ was done on the semi-industrial implanter [5] in vacuum, the current density did not exceed $0.1 \mathrm{~mA} / \mathrm{cm}^{2}$.

DRON-4 and Rigaku RINT-2500V X-ray diffractometers with the position-sensitive proportional counter (PSPC/MDGT) were applied for the investigations of structure and substructure, as well as the phase composition of the coatings. The operating voltage and current of the X-ray diffractometers were $40 \mathrm{kV}$ and $300 \mathrm{~mA}$, respectively. The X-ray diffraction (XRD) spectra were measured under the angles of $2,3,10$, and 30 degrees for the as-deposited samples. Phase-structure state of the coatings was investigated using DRON-4 with $\mathrm{Cu} K_{\alpha}$ irradiation of $\lambda=0.154178 \mathrm{~nm}$ with a graphite monochromator in the secondary beam. Diffraction spectra for the phase analysis were taken using $\theta-2 \theta$ scans with BraggBrentano, which were focused in the range of the angles $25-140^{\circ}$. The research was carried out in a spot mode with the scan step $\Delta(2 \theta)=0.02^{\circ}$, the pulse accumulation time at each point was $10-100 \mathrm{~s}$ depending on the width and intensity of diffraction maxima. Microanalysis with the energy-dispersive spectroscopy (EDS) on the scanning electron microscope JEOL-7000F (Japan) and the secondary ion mass-spectrometry (SIMS) on the TOF spectrometer ULVAC-PHI TRIFTV nanoTOF (Physical Electronics, Japan) were used for the investigations of the elemental composition of coatings.

The Rutherford backscattering (RBS) was used to investigate the distribution of elements near the surface.
The energy of ${ }^{4} \mathrm{He}^{+}$ions was $1.4 \mathrm{MeV}$; the energy resolution of the detector was $16 \mathrm{keV}$ for RBS studies [14]. In addition, we used the scanning electron microscope with the energy-dispersive spectrometer JSM-6010 LA (JEOL, Japan). Measurements were done in low vacuum, the accelerating voltage was $20 \mathrm{kV}$. Investigations of structure and phase composition were carried out using the electron microscope JEOL JEM-2100F with the energy of electrons $200 \mathrm{keV}$. Lamellas were preliminarily prepared using the focused ion beam. Microhardness and elasticity modulus were measured using the dynamic indentation of the Berkovich pyramid (Triboindentor TI-950, HYSITRON Inc., Oliver-Pharr methodology). The load on the indenter varied from 500 to $10000 \mu \mathrm{N}$.

\section{Results and discussion}

Figure 1a shows the XRD spectra of the coatings under different nitrogen pressures in the deposition chamber. It can be clearly seen that a phase with the fcc-lattice was formed as the main phase. It is quite characteristic of the structures of multielement alloy nitrides. The mean size of crystallites of fcc-phase in the coatings was $8 \mathrm{~nm}$ in the case of low pressure, it was defined using the Scherrer formula. Thus, the preferred orientation of crystallites growth with the plane (200), parallel to the surface, was formed. The texture axis [100] was perpendicular to the surface plane in this case. These coatings demonstrated high hardness up to $51 \pm 0.7 \mathrm{GPa}$ according to the hardness measurements using the Vickers method. The spectrum 2 of Fig. 1a corresponds to the coating, fabricated under comparatively high pressure $3 \times 10^{-4}$ Torr. We can see fundamental difference: preferred orientation of the plane (111), parallel to the plane of growth, appeared in the form of significant increase of intensity of its peaks. Mean size of crystallites of fcc-phase of the coating, deposited under much greater pressure, also increased and equaled $17-20 \mathrm{~nm}$. The depth distribution of the coating elements is illustrated in Fig. 1b. From the presented EDS results one can see that the concentration of nitrogen reached the highest values near the surface of the coating.

The results of RBS analysis of the as-deposited and implanted coatings (sample from series 2) are presented in Fig. 2a and b. A sharp "ledge" is observed between $\mathrm{Ti}, \mathrm{Zr}, \mathrm{V}, \mathrm{Nb}$ from the one side and $\mathrm{Ta}$, Hf elements from the other side (Fig. 2a). Stoichiometry has changed throughout the whole depth of the analysis for the implanted coatings. Moreover, we observe blurring of the ledge of the RBS spectrum in the channel range $(400 \div 440)$ in Fig. 2a in comparison with the channel range $(390 \div 425)$ in Fig. $2 \mathrm{~b}$ due to the processes of atomic collisions, formation of collision cascades, ion mixing and accelerated radiation diffusion. It was rather difficult to distinguish Hf and Ta, due to their almost equal atomic masses [29]. Elemental distribution in the surface and subsurface layer is non-uniform. It is explained by different processes during deposition, such as re-sputtering, 

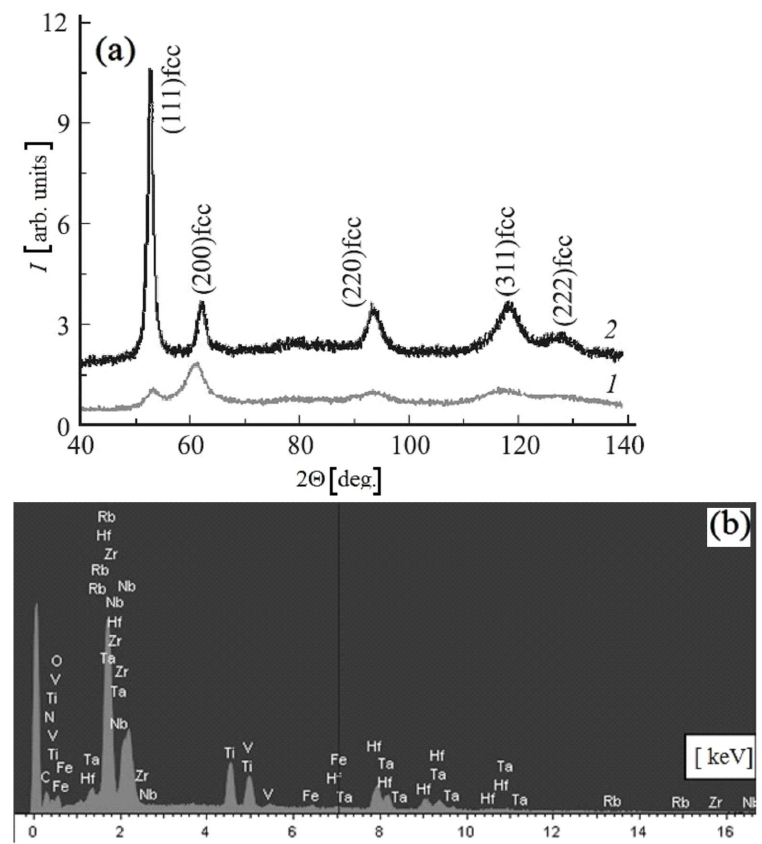

Fig. 1. Parts of diffraction spectra of the (TiZrHfVNbTa) N coatings from series 1 (curve 1) and 2 (curve 2) (a) and elemental microanalysis on the cross-section of the sample from the series 1 (b).

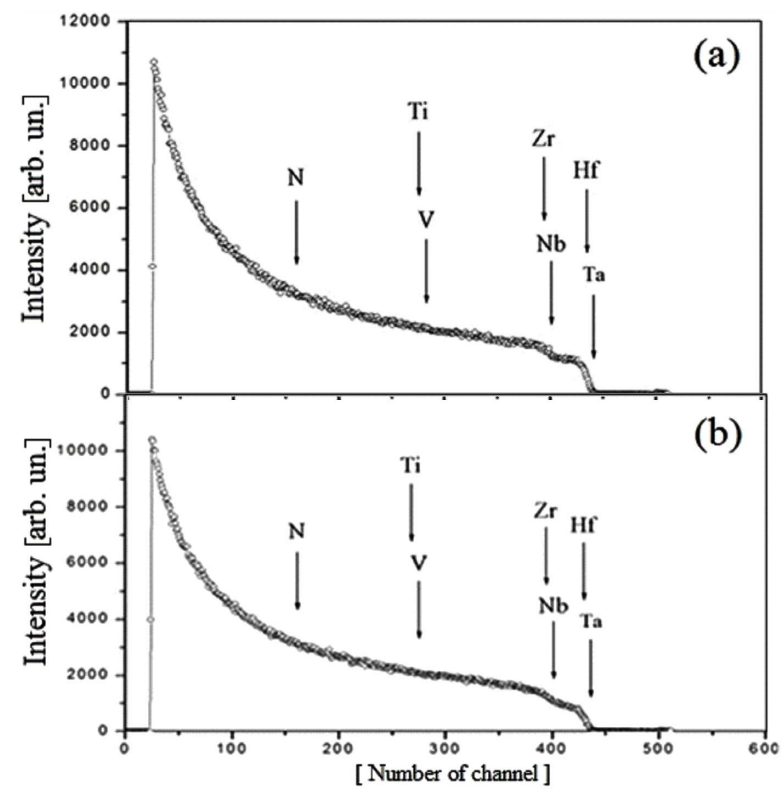

Fig. 2. Rutherford backscattered spectra of the sample from series 2 before (a) and after (b) ion implantation.

etc. However, in the depth of the coating, elemental distribution is quite homogeneous, as it follows from the RBS data. We should point out that for the calculation of the projective range of the $\mathrm{N}^{+}$ions we used standard software, but it was very hard to calculate profiles of $\mathrm{N}^{+}$ ions due to quite high roughness of the coating's surfa- ces after vacuum-arc deposition. Nevertheless, we could conclude that the elemental concentration was homogeneous along the thickness of the as-deposited coating. Ion implantation led to partial sputtering of the surface layer; concentration of $\mathrm{N}^{+}$ions increased up to 90 at.\%. Average concentrations of $\mathrm{Ti}, \mathrm{Zr}, \mathrm{Hf}, \mathrm{V}, \mathrm{Nb}$, and Ta were: $7 \div 10$ at. $\%, 7.7 \div 9.8$ at. $\%, 8 \div 12$ at. $\%, 5 \div 6.5$ at. $\%$, $8.1 \div 9.9$ at. $\%$, and $4.2 \div 5$ at. $\%$, respectively.

The profilogram taken from the surface of the asdeposited (TiZrHfVNbTa)N coating from series 1 shows that deposition led to an increase of surface roughness due to the droplet fractions of the plasma flux (Fig. 3). Further studies of the wear track clearly show that the material losses take place and wear debris was observed during the wear tests at the edges of the wear track. For a large wear track we observed material loss due to abrasive wear. The maximum depth of the wear track was $10.4 \mu \mathrm{m}$, the area of the hole was $4001 \mu \mathrm{m}^{2}$, and its maximum height was $0.862 \mu \mathrm{m}$ (Fig. 3b). After nanoindentation we found that maximum values of nanohardness and elasticity modulus were $26 \mathrm{GPa}$ and 230-240 GPa, respectively (coatings from series 1 ). The hardness of the coatings from series 2 with a higher nitrogen concentration increased to $34.6 \mathrm{GPa}$.

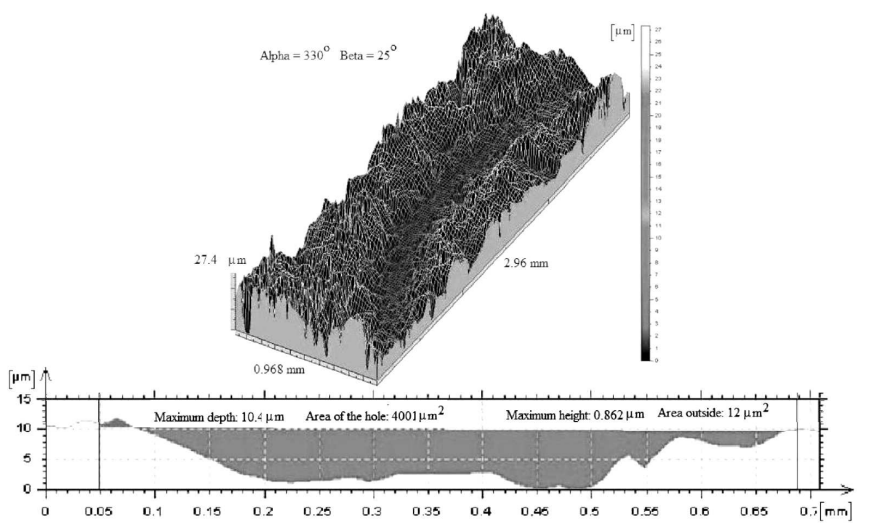

Fig. 3. 3D image (top) and profilogram (bottom) of friction track surface for (TiZrHfVNbTa) N coating from series 1 .
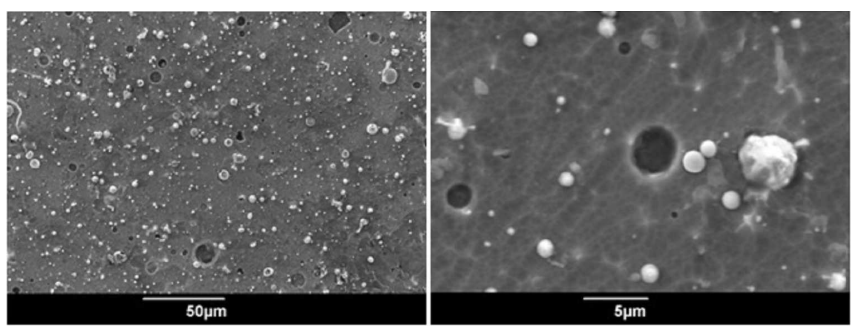

Fig. 4. SEM image of the (TiZrHfVNbTa)N coatings from series 1 .

Implantation of $\mathrm{N}^{+}$ions (the fluence was $10^{18} \mathrm{~cm}^{-2}$ ) led to decrease of hardness up to $18 \mathrm{GPa}$. The hardness 


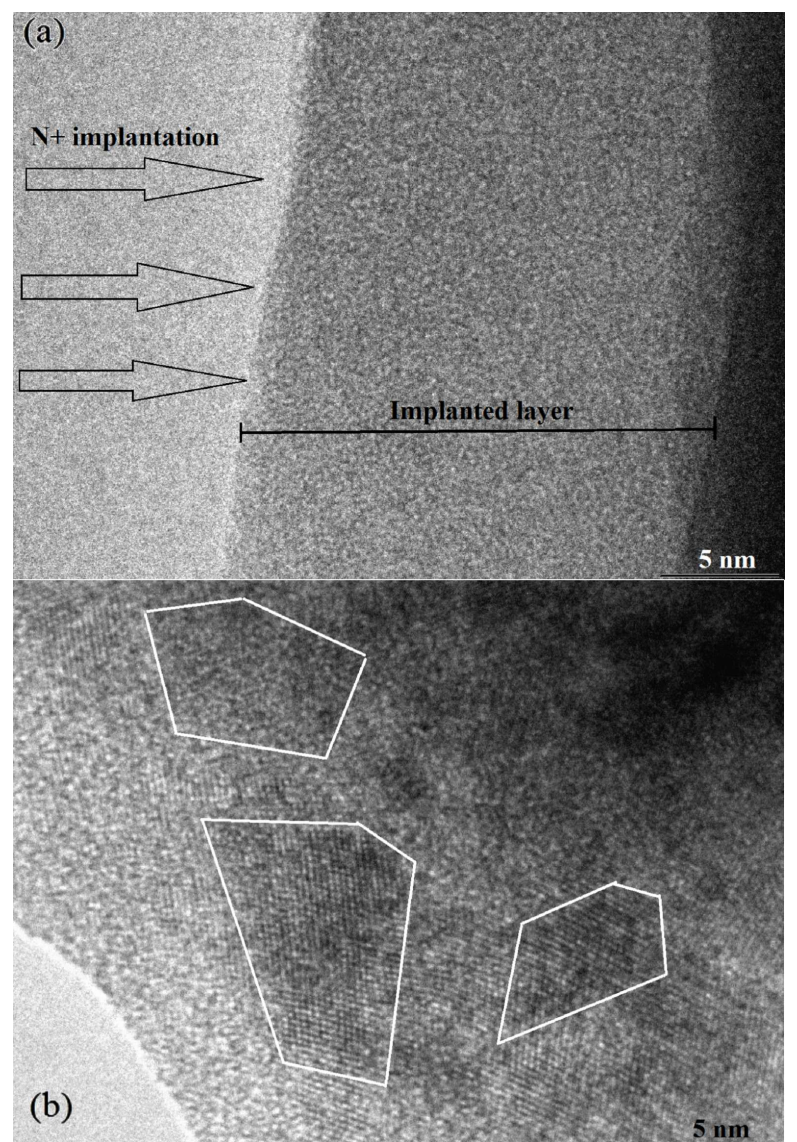

Fig. 5. TEM images of the cross-sections of the (TiZrHfVNbTa)N coatings (sample from series 2): near-thesurface layer (a) and region with marked nanocrystallites (b).

started increasing with the increase of the depth and it achieved the maximum (23 GPa) at the depth $\geq 200 \mathrm{~nm}$. Figure 4 presents the images of the surface of the (TiZrHfVNbTa)N coating from series 2 after ion implantation. There can be observed the decrease of the surface coating roughness which can be explained by thin layer sputtering from the coating surface. Typical droplet fractions can be clearly seen. Such fractions usually formed during vacuum-arc evaporation of the cathode due to the absence of separation. The coating cross-section view is presented in Fig. 4b, the coating thickness is around $6.3 \mu \mathrm{m}$. After the EDS analysis it can be stated that distribution of elements along the coating depth indicates its homogeneity within the error of the EDS method.

The projected range of $\mathrm{N}^{+}$ions with the energy $60 \mathrm{keV}$ is $68-72 \mathrm{~nm}$ depending on the elemental composition and concentration of refractory metal nitrides of the coating. As can be seen from the transmission electron microscopy (TEM) investigations (part of the coating with the marked nanograins is presented in Fig. 5), the amorphous layer thickness is greater than $40 \mathrm{~nm}$. The nanocrystal layer with nanocrystals of the size $5-6 \mathrm{~nm}$ is located under this amorphous layer. The phase analysis of this layer showed the presence of fcc phase, based on the solid solution, in which $\mathrm{Ti}, \mathrm{Hf}, \mathrm{Zr}, \mathrm{V}, \mathrm{Nb}$, Ta were randomly distributed in the sublattice (see Fig. 4). Lattice planes and their borders are clearly seen. Based on the microdiffraction data, it can be stated that the interplanar spaces in (100) plane with the fcc lattice are equal to $0.235 \mathrm{~nm}$ (200) and $0.205 \mathrm{~nm}$ (202). In addition, the increase of interplanar spacing up to $0.255-0.259 \mathrm{~nm}$ (plane (111)) and $0.226 \mathrm{~nm}$ (plane (200)) far from the surface of the nanostructured coating can be observed. Such values are close to those obtained by the XRD data. Reflections with $0.275-0.278 \mathrm{~nm}$ interplanar spaces can be seen at the depth of $180 \mathrm{~nm}$. It is known that the fcc and hcp lattices are quite similar in their internal energy with small energy barrier sufficient for transformation. The interplanar space $0.275-0.278 \mathrm{~nm}$ corresponds to (100) plane for nitrides of transition metals with the hcp lattice. Therefore, it can be assumed that in the local regions of the coating lattice transformation from fcc to hcp can occur by a shear mechanism due to composition inhomogeneity associated with a relatively low nitrogen content (low working pressure during deposition). The driving force of this process is the great thermodynamic stability of the hcp lattice with a deficiency of nitrogen atoms in the octahedral interstices.

\section{Conclusions}

Multielement nanostructured (TiHfZrNbVTa)N coatings were deposited on steel substrates using the vacuum-arc evaporation technique under different deposition conditions. Increasing of the nitrogen pressure in the deposition chamber led to a significant increase of nitrogen concentration in the coatings and to decrease of the concentration of such component elements as $\mathrm{Ti}, \mathrm{V}, \mathrm{Nb}$. In addition, it led to formation of preferred orientation of the (111) plane and the hcp lattice. The nanostructured multielement coatings were subjected to ion implantation by very high fluences of $\mathrm{N}+$ ions $\left(10^{18} \mathrm{~cm}^{-2}\right)$, which led to formation of a multilayered structure, composed of amorphous, nanocrystalline and nanostructure layers. Hardness of the implanted coatings decreased to $18 \mathrm{GPa}$ in the near-surface amorphous layer and increased with the depth to $26 \mathrm{GPa}$. This can be explained by sputtering of a thin layer from the coating surface which led to roughness decrease due to exclusion of droplet fraction which was formed because of cathode erosion during vacuum-arc deposition. The plasticity index $H / E$ increased and exceeded the value of 0.1 , thus the fabricated coatings are considered to have good wear resistance.

\section{Acknowledgments}

The work was partially financed by the budget programs "Development of materials science basis of structure engineering of vacuum-plasma superhard coatings in order to achieve necessary functional properties" (No. 
0115U000685), "Physical basis of forming of composition and properties of nanostructured boride, nitride and boron-nitride films of refractory metals for their usage in machine building" (No. 52.22.02-01.16/18.ZF) and "Development of perspective nanostructured multilayered coatings with enhanced physical-mechanical and tribological properties" (No. 0116U006816). The authors are very grateful to Prof. G. Abadias for his assistance in stress measurements, to A.V. Pshyk for his assistance in nanohardness and elasticity modulus measurements, to D.A. Kolesnikov for his assistance in scratch tests, to Prof. O.V. Sobol for his consultations in the XRD studies and to Dr. N. Levintant-Zayonts for the assistance in samples implantation. We are also grateful to the NanoBioMedical Centre, Adam Mickiewicz University (Poznań, Poland) for the opportunity of using the Triboindentor TI-950 device.

\section{References}

[1] A.D. Pogrebnjak, A.M. Tolopa, Nucl. Instrum. Methods Phys. Res. B 52, 24 (1990).

[2] F.F. Komarov, Ion Beam Modification of Metals, Gordon and Breach, Philadelphia 1992.

[3] V.I. Lavrentiev, A.D. Pogrebnjak, Surf. Coat. Technol. 99, 24 (1998).

[4] O.M. Ivasishin, A.D. Pogrebnjak, S.N. Bratushka, Nanostructured Layers and Coatings Formed by IonPlasma Fluxes in Titanium Alloys and Steels, Akademperiodika, Kiev 2011.

[5] A.D. Pogrebnjak, S.N. Bratushka, V.M. Beresnev, N. Levintant-Zayonts, Russ. Chem. Rev. 82, 1135 (2013).

[6] O.N. Senkov, S.V. Senkova, D.M. Dimiduk, C. Woodward, D.B. Miracle, J. Mater. Sci. 47, 6522 (2012).

[7] G. Salishchev, M.A. Tikhonovsky, D.G. Shaysultanov, N.D. Stepanov, A.V. Kuznetsov, I.V. Kolodiy, A.S. Tortika, O.N. Senkov, J. Alloys Comp. 591, 11 (2014).

[8] L. Thome, S. Moll, J. Jagielski, A. Debelle, F. Garrido, G. Sattonnay, Acta Phys. Pol. A 120, 7 (2011).

[9] N. Levintant-Zayonts, S. Kucharski, Acta Phys. Pol. A 120, 79 (2011).

[10] J. Jagielski, U. Ostaszewska, D. Bielinski, A. Piatkowska, M. Romaniec, Acta Phys. Pol. A 123, 888 (2013).

[11] V. Braic, A. Vladescu, M. Balaceanu, C.R. Luculescu, M. Braic, Surf. Coat. Technol. 211, 117 (2012).

[12] D.C. Tsai, Y.L. Huang, S.R. Lin, S.C. Liang, F.S. Shieu, Appl. Surf. Sci. 257, 1361 (2010).

[13] A.D. Pogrebnjak, A.A. Bagdasaryan, I.V. Yakushchenko, V.M. Beresnev, Rus. Chem. Rev. 83, 1027 (2014).
[14] A.D. Pogrebnjak, I.V. Yakushchenko, A.A. Bagdasaryan, O.V. Bondar, R. Krause-Rehberg, G. Abadias, P. Chartier, K. Oyoshi, Y. Takeda, V.M. Beresnev, O.V. Sobol, Mater. Chem. Phys. 147, 1079 (2014).

[15] T.N. Koltunowicz, J. Mater. Sci. Mater. Electron. 26, 6450 (2015).

[16] T.N. Kołtunowicz, P. Żukowski, V. Bondariev, J.A. Fedotova, A.K. Fedotov, Vacuum 120B, 44 (2015).

[17] P. Zhukowski, J. Sidorenko, T.N. Kołtunowicz, J.A. Fedotova, A.V. Larkin, Przeglad Elektrotechniczny 86, 296 (2010), (in Polish).

[18] J.V. Kasiuk, J.A. Fedotova, T.N. Koltunowicz, P. Zukowski, A.M. Saad, J. Przewoznik, Cz. Kapusta, J. Zukrowski, I.A. Svito, J. Alloys Comp. 586, S432 (2014).

[19] D.B. Miracle, O.N. Senkov, Acta Mater. 122, 448 (2017).

[20] A.D. Pogrebnjak, I.V. Yakushchenko, O.V. Sobol', V.M. Beresnev, A.I. Kupchishin, O.V. Bondar, M.A. Lisovenko, H. Amekura, K. Kono, K. Oyoshi, Y. Takeda, Techn. Phys. 60, 1176 (2015).

[21] A.D. Pogrebnjak, I.V. Yakushchenko, O.V. Bondar, O.V. Sobol, V.M. Beresnev, K. Oyoshi, H. Amekura, Y. Takeda, Tech. Phys. Lett. 41, 1054 (2015).

[22] A.D. Pogrebnjak, I.V.Yakushenko, O.V. Bondar, O.V. Sobol, V.M. Beresnev, K. Oyoshi, H. Amekura, Y. Takeda, Phys. Solid State 57, 1559 (2015).

[23] Y. Zhao, S.M. Wong, H.M. Wong, S. Wu, T. Hu, K.W.K. Yeung, P.K. Chu, ACS Appl. Mater. Interf. 5, 1510 (2013).

[24] S. Kucharski, N. Levintant-Zayonts, J. Luckner, Mater. Des. 56, 671 (2014).

[25] X. Feng, G. Tang, X. Ma, M. Sun, L. Wang, Nucl. Instrum. Methods Phys. Res. B 301, 29 (2013).

[26] V.V. Uglov, G. Abadias, A.Y. Rovbut, S.V. Zlotski, I.A. Saladukhin, V.A. Skuratov, S. Petrovic, Nucl. Instrum. Methods Phys. Res. B 354, 269 (2015).

[27] A.D. Pogrebnjak, G. Abadias, O.V. Bondar, O.V. Sobol, V.M. Beresnev, A.V. Pshyk, A.A. Demianenko, K.O. Belovol, D.A. Kolesnikov, H. Komsta, Acta Phys. Pol. A 125, 1284 (2014).

[28] A.V. Khomenko, I.A. Lyashenko, Fluctuat. Noise Lett. 7, L111 (2007).

[29] Y.F. Ye, Q. Wang, Y.L. Zhao, Q.F. He, J. Lu, Y. Yang, J. Alloys Comp. 681, 167 (2016). 